\title{
Proteolytic Processing of $\beta$-Amyloid Precursor by Calpain I
}

\author{
Robert Siman, ${ }^{1}$ J. Patrick Card, ${ }^{2}$ and Leonard G. Davis ${ }^{2}$ \\ 'Cephalon, Inc., West Chester, Pennsylvania 19380, and ${ }^{2}$ Medical Products Department, The DuPont Company, \\ Wilmington, Delaware 19880
}

The $\beta$-amyloid peptide is a core component of the neuritic plaques that accumulate in Alzheimer's disease. Since the $\beta$-peptide resides within a family of precursor proteins (APPS), proteolytic processing of APP is required for $\beta$-amyloid deposition into plaques. Here, we have examined the role played by the calcium-dependent cysteine protease calpain I in APP processing. Immunoblotting with a specific APP antiserum was used to assess the in vitro degradation of rat brain APP, which appears as a triplet of polypeptides of $M_{r} 110-130$ $\mathrm{kDa}$. Both soluble and membrane-bound APP were extraordinarily sensitive to activated calpain I. APP contains at least 3 distinct calpain I cleavage sites. The most protease-sensitive site was located within the highly acidic structural motif called the PEST domain, a second site was upstream of the putative $\mathrm{N}$-linked glycosylation sites, and a third generated a $16 \mathrm{kDa}$ carboxy-terminal fragment that contains the $\beta$-peptide. Based on light microscopic immunohistochemistry, APP and calpain I were extensively colocalized within large numbers of neurons distributed throughout the rat brain, with especially high levels of each in neocortical layer 5 , subiculum, globus pallidus, entopeduncular nucleus, anterodorsal and reticular thalamic nuclei, motor trigeminal nucleus, deep cerebellar nuclei, and Purkinje cells. Both antigens were most prevalent within neuronal perikarya. Intraventricular kainate infusion, which is known to cause rapid activation of hippocampal calpain I, produced a $32 \%$ decline in APP levels after $24 \mathrm{hr}$, suggestive of in vivo degradation of APP by calpain I. Following kainate-induced neuronal loss, both APP and calpain I immunoreactivities appeared in the surrounding reactive astroglia. These results indicate that calpain I may be involved in the normal and, perhaps, pathological processing of APP, and that this processing could occur in either neurons or reactive astrocytes. Calcium influx and calpain I activation may provide a mechanism by which excitatory neurotransmission regulates APP metabolism.

Filamentous deposits of amyloid, called plaques, are a hallmark of the neuropathology of Alzheimer's disease, accumulating in the extracellular space (neuritic plaques) and cerebrovasculature (vascular and meningeal plaques; Terry and Katzman, 1983). One of the major core components of plaques has been identified as an $M_{\mathrm{r}} 4500 \mathrm{Da}$ peptide called $\beta$-amyloid (Glenner and Wong, 1984 ) or $\Lambda 4$ (Masters et al., 1985). The cloning of cDNAs cn-

\footnotetext{
Received Jan. 2, 1990; revised Mar. 16, 1990; accepted Mar. 26, 1990.

We thank J. C. Noszek, C. Kegerise, and R. Lampe for excellent technical assistance, and the Blood Bank of Delaware for supplying the human erythrocytes.

Correspondence should be addressed to Robert Siman, Cephalon Inc., 145 Brandywine Parkway, West Chester, PA 19380.

Copyright (C) 1990 Society for Neuroscience $0270-6474 / 90 / 072400-12 \$ 03.00 / 0$
}

coding $\beta$-amyloid has revealed that the peptide resides within a family of closely related precursor proteins (APP; Goldgaber et al., 1987; Kang et al., 1987; Robakis et al., 1987; Tanzi et al., 1987, 1988; Kitaguchi et al., 1988; Ponte et al., 1988). The APP sequences are predictive of integral membrane glycoproteins, with $\beta$-amyloid comprising part of the extracellular and transmembrane domains (Kang et al., 1987). Synthetic peptides based on the $\beta$-amyloid sequence spontaneously form highly insoluble aggregates that resemble those found in plaque cores (Castano et al., 1986; Kirschner et al., 1987). These observations suggest that APP is normally proteolytically processed so as not to generate $\beta$-amyloid, but under pathological conditions the APP processing mechanism may be altered. Indeed, abnormal proteolysis of APP has been proposed as an early and fundamental step in the pathogenesis of plaques (Glenner and Wong, 1987; Kang et al., 1987; Grundke-Iqbal et al., 1989; Weidemann et al., 1989). Three recent findings further implicate alterations in proteolysis in plaque formation. First, the protease inhibitor $\alpha_{1}$-antichymotrypsin has been identified as another major plaque component (Abraham et al., 1988). Second, 2 of the 3 known APPs contain a domain sharing considerable homology with Kunitz-type serine protease inhibitors (Kitaguchi et al., 1988; Ponte et al., 1988; Tanzi et al., 1988). Third APPs have a primary structure motif composed of proline $(\mathrm{P})$, glutamic acid (E), serine (S), and threonine (T), called a PEST sequence (Siman and Christoph, 1989), that is highly predictive of the class of most rapidly turning over proteins (Rechsteiner et al., 1987; Rogers et al., 1986). Consistent with an unusual sensitivity to degradation, at least a fraction of APP reportedly has an extremely short half-life in vitro (Weidemann et al., 1989).

For an understanding of the normal and pathological processing of APP, a number of key issues need to be addressed: what are the proteases responsible for APP processing, where within the APP molecules are the sites of cleavage, in what tissue compartment does processing occur, and what factors regulate this processing? Several proteases have been described in the brain that must be considered as candidates for APP processing. These include members of all 4 classes of protease: cysteine- (calpains I and II, cathepsin B; Suhar and Marks, 1979; Murachi 1983), aspartic- (cathepsin D, renin; Whitaker and Seyer, 1979; Slater et al., 1980), serine- (plasminogen activator, cathepsin A, clipsin; Bowen and Davison, 1973; Soreq and Miskin, 1983; Nclson and Siman, 1990), and metallo-protcases (MP92, MP-70, MP-65; Nelson and Siman, 1989). On the basis of cleavage specificities alone, it is difficult to predict which of these proteases may be important for APP degradation. In many cases, the preferred primary sequences at substrate cleavage sites are not known, and for some proteases, it is only the secondary or tertiary substrate conformation that is the key determinant 
(Suzuki et al., 1987). One prediction can be made, however, because the identification of PEST sequences in APPs leads to the suggestion that the protcins may be high-affinity substrates for calpain (Siman and Christoph, 1989). Accordingly, we have used 3 approaches to assess the role of calpain in APP processing. First, immunoblotting with an antiserum specific for APP was used to examine the in vitro degradation of APP by calpain I and several other proteases. Second, the localization of APP in normal and experimentally damaged rat brain was compared with that of calpain I using immunohistochemistry. Last, APP levels were quantified following intracerebral kainate infusion, a treatment known to activate calpain I in vivo (Siman and Noszek, 1988; Siman et al., 1989b). Collectively, the results implicate calpain $I$ in the normal and, perhaps, pathological processing of APP.

\section{Materials and Methods}

Calpain I purification. Calpain I was purified from rat or human erythrocyte cytosol using methods described by Yoshimura et al. (1983) and Croall and DeMartino (1983). Washed erythrocytes from 0.5 liter blood

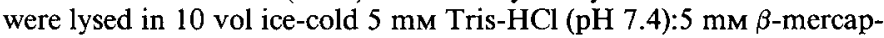
toethanol:0.5 mM EGTA:0.5 mM EDTA and centrifuged at 20,000 $\times$ $g$ for $20 \mathrm{~min}$. The supernatant was dialyzed against buffer A $20 \mathrm{~mm}$ Tris- $\mathrm{HCl}(\mathrm{pH}$ 7.4):5 mM $\beta$-mercaptoethanol:1 mM EGTA:1 mM EDTA] containing $50 \mathrm{~mm} \mathrm{NaCl}$. Following centrifugation at $20,000 \times g$ for 20 min, the supernatant was fractionated on columns of DEAE-cellulose, Ultrogel AcA-34, phenyl-Sepharose CL-4B, blue-Sepharose CL-6B, and DEAE-Biogel A. Calpain activity in the fractions was determined by calcium-stimulated ${ }^{14} \mathrm{C}$-caseinolysis (Simonson et al., 1985). Typical yields ranged hetween 1.5 and $3 \mathrm{mg}$ protein. The enzyme appeared electrophoretically homogeneous based on the presence of the $84 \mathrm{kDa}$ catalytic subunit and the $28 \mathrm{kDa}$ light chain, and the absence of additional polypeptides.

Antibodies to calpain I. Two antibodies were raised. One is a polyclonal antibody to the catalytic subunit of human erthrocyte calpain I, and the other is a monoclonal antibody to the rat erythrocyle protedse. Human erythrocyte calpain I was used to immunize rabbits according to previously published procedures (Siman and Noszek, 1988). Initial bleeds reacted only with the $84 \mathrm{kDa}$ catalytic subunit, while later bleeds also contained antibodies to the $28 \mathrm{kDa}$ light chain, as evidenced by Western blot analysis (see below). Immunoglobulin $\mathrm{G}$ fractions were prepared from immune sera by chromatography on protein A-Sepharose CL-4B. Sera were diluted with equal volumes of $20 \mathrm{~mm}$ Tris- $\mathrm{HCl}(\mathrm{pH}$ 7.4):0.5 M NaCl and loaded onto columns equilibrated with the same buffer. Following sample application, the columns were washed with 5 vol buffer, and bound material was eluted with $0.2 \mathrm{M}$ glycine- $\mathrm{HCl}(\mathrm{pH}$ $2.5): 0.5 \mathrm{M} \mathrm{NaCl}$ and immediately neutralized with Tris base. The fractions were stored in aliquots at $-80^{\circ} \mathrm{C}$.

The monoclonal antibody was prepared by fusion of the myeloma cell line Ag.X63.6.5.3 with spleen cells from a mouse immunized with rat erythrocyte calpain I (Goding, 1986). Hybridomas were selected with hypoxanthine-aminopterin-thymidine, and antibody-secreting hybridomas were identified by an ELISA using rat erythrocyte calpain I-coated microtiter plates as the solid phase. One hybridoma was used in the present study (DUP1). It was cloned twice by limiting dilution in the presence of endothelial cell growth supplement (Collaborative Research; Westerwoudt, 1986), then grown in large culture flasks to generate conditioned medium. DUP1 was identified as an IgM using a subtyping ELISA (Boehringer). The antibody was precipitated from the conditioned medium with $60 \%$ saturated ammonium sulfate, dialyzed against $20 \mathrm{~mm}$ Tris- $\mathrm{HCl}(\mathrm{pH}$ 7.4):0.15 M NaCl, filter-sterilized, and stored at $4^{\circ} \mathrm{C}$.

Western blot analysis. The $\beta$-amyloid precursor protein (APP) was identified by immunoblotting with an antiserum to a synthetic peptide corresponding to the carboxy-terminal 20 amino acids (residues 676695 , according to Kang et al., 1987). Preparation of this peptide, the antiserum to it, and use of the antiserum in Western blot analysis have been previously described (Card et al., 1988; Siman et al., 1989a). In some experiments, an additional step was added to the immunostaining procedure in order to increase detection sensitivity: incubation with alkaline phosphatase-conjugated rabbit anti-goat IgG (Cappel, 1:500) after the incubation in alkaline phosphatase-conjugated goat anti-rabbit IgG. Preabsorption was carried out by incubation of diluted antiserum 385 for $1 \mathrm{hr}$ at $22^{\circ} \mathrm{C}$ with the peptide immunogen at $50 \mu \mathrm{g} / \mathrm{ml}$; the antiserum was then used for Western blotting as described above.

The specificity of an antiserum to human erythrocyte calpain I was monitored by Western blotting. The antiserum was diluted 1:1000 and used as described above.

Proteolysis of APP. In most experiments, purified proteases were incubated with rat brain crude membrane preparations; APP degradation was assessed by immunoblotting, while overall protein breakdown was determined by Coomassie blue staining of identical gels. Tissues were homogenized by sonication in 10 vol buffer $B$ [buffer $A$ plus the protease inhibitors leupeptin $(50 \mu \mathrm{M})$, phenylmethylsulfonylfluoride $(100 \mu \mathrm{M})$, and pepstatin A $(50 \mu \mathrm{M})]$, and centrifuged at $14,000 \times g$ for $20 \mathrm{~min}$. Pellets were resuspended in buffer $A$ and centrifuged 2 additional times. The final pellet was resuspended in buffer $A$ to a protein concentration of $7 \mathrm{mg} / \mathrm{ml}$, as determined by the method of Bradford (1976). Proteolysis reactions were performed at $22^{\circ} \mathrm{C}$ and contained $70 \mu \mathrm{g}$ membrane protein. For activation of calpain $\mathrm{I}, \mathrm{CaCl}_{2}$ was added to $4 \mathrm{~mm}$. Reactions were stopped by the addition of electrophoresis sample buffer, followed by heating to $90^{\circ} \mathrm{C}$ for $5 \mathrm{~min}$. In the experiments described in Figure 3 , APP was extracted from membranes prior to proteolysis by treatment with $1 \%$ Triton $\mathrm{X}-100$ for $30 \mathrm{~min}$ at $4^{\circ} \mathrm{C}$, followed by centrifugation at $14,000 \times g$ for $20 \mathrm{~min}$.

APP content was quantified by scanning densitometry of the $M_{\mathrm{r}} 110$ $130 \mathrm{kDa}$ immunostained polypeptides according to methods published previously for immunological quantitation of other proteins (Siman and Noszek, 1988; Siman et al., 1989a). Relative APP levels from proteasetreated samples were compared with control, nontreated, samples run on the same gels. APP content was found to be linear with respect to the total protein loaded over about a 10 -fold range. Identical gels were stained with Coomassie blue and, following destaining, the major membrane polypeptides were quantified by scanning densitometry.

For experiments on the effect of calpain I activation on APP content of hippocampus in vivo, injections of $0.8 \mu \mathrm{g}$ kainate were stereotaxically placed into the lateral ventricle of chloropent-anesthetized rats using the method described previously (Siman and Noszek, 1988; Siman et al., 1989b). For this experiment, 10 rats were injected with kainate, 4 with saline vehicle, and 8 were not injected. Dorsal hippocampi were removed after $24 \mathrm{hr}$ and used to generatc crudc mcmbrane preparations as described above. For the study of the effect of neuronal damage on the distributions of APP and calpain I immunoreactivities, the same injection procedure was used, except that the dose of kainate was reduced to $0.5 \mu \mathrm{g}$. A total of 4 rats were used for this experiment. Rats were processed for immunohistochemistry $5 \mathrm{~d}$ later.

Immunohistochemistry. Rats were deeply anesthetized with sodium pentobarbital and perfused intracardially with $0.1 \mathrm{M}$ sodium phosphate (PB), followed by $4 \%$ paraformaldehyde in $\mathrm{PB}$. Brains were post-fixed for $2-3 \mathrm{hr}$, then cryoprotected overnight in $25 \%$ sucrose in PB. Sections, $35 \mu \mathrm{m}$ thick, were cut in the coronal or sagittal planes with a freezing microtome and immunostained according to published procedures (Card et al., 1988; Siman et al., 1989a). In addition to an antiserum to the carboxy-terminal domain of APP (antiserum 385), an antibody directed at the carboxy portion of the $\beta$-amyloid pcptide (rcsiducs $619-638$, according to Kang et al., 1987; antiserum 384) was also used. The properties of both of the APP antisera in immunohistochemical studies have been detailed previously (Card et al., 1988; Siman et al., 1989a). Primary antibodies were used at dilutions of 1:500 (antisera to APP), 1:2000 (rabbit anti-human erythrocyte calpain I, $84 \mathrm{kDa}$ subunit), or $1: 2$ (mouse anti-rat erythrocyte calpain I, IgM fraction). Bound antibodies were visualized by sequential incubations in biotinylated antirabbit or anti-mouse IgG, avidin-peroxidase conjugate, and a diaminobenzidine/hydrogen peroxide substrate solution. Controls included sections processed as described above, but without the use of a primary antibody and preabsorption of primary antibodies with immunogens at $50 \mu \mathrm{g} / \mathrm{ml}$. There was little or no staining observed under the control conditions.

Partial purification of rat brain APP. APP was cxtracted from rat brain membranes with 10 vol $\mathrm{H}_{2} \mathrm{O}$; the suspension was stirred at $4^{\circ} \mathrm{C}$ for 1 $\mathrm{hr}$, then centrifuged at $40,000 \times \mathrm{g}$ for $30 \mathrm{~min}$. The supernatant contained about $75 \%$ of the APP as determined by Western blotting (Lampe et al., 1989). It was dialyzed against buffer $B$ and loaded onto a column of DEAE-Biogel A that had been equilibrated with buffer B. APP eluted in the flow-through fraction. This fraction was treated for $30 \mathrm{~min}$ at $4^{\circ} \mathrm{C}$ with $0.5 \%$ Trition $\mathrm{X}-100$, then loaded onto another DEAE-Biogel 
A
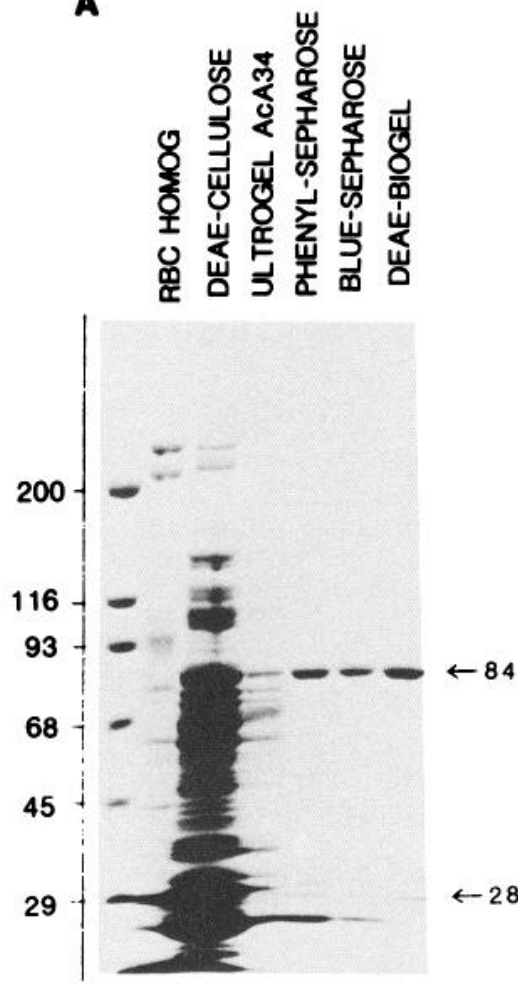

COOMASSIE BLUE
B

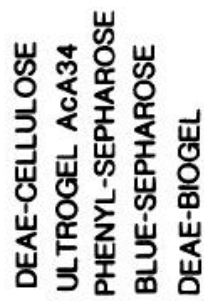

IMMUNOBLOT

Figure 1. Purification of human erythrocyte calpain I and characterization of antibodies. A, Calpain I was purified from human erythrocyte cytosol by methods described in Yoshimura et al. (1983) and Croall and DeMartino (1983). Shown here are the polypeptide compositions of calpain I-containing fractions, separated on a 5-15\% linear gradient gel and stained with Coomassie blue. The purified protease appears electrophoretically homogeneous and consists of 84 and $28 \mathrm{kDa}$ subunits in an approximately $1: 1$ molar stoichiometry (3:1 stoichiometry by weight). Molecular weight standards are shown in the left lane, and their weights (in kilodaltons) are indicated in the left margin. B, Immunoblot analysis of calpain I-containing fractions with polyclonal antibodies. Initial bleeds contained antibodies to the $84 \mathrm{kDa}$ catalytic subunit.

column. APP bound to the column and was eluted with a linear gradient of $\mathrm{NaCl}$ to $500 \mathrm{~mm}$. APP-containing fractions were identified by Western blotting, pooled, placed in dialysis tubing, and concentrated 10 -fold using Aquacide II (Calbiochem). The preparation was stored at $-80^{\circ} \mathrm{C}$.

\section{Results}

Calpain I purification and antibody production

For the study of in vitro degradation of APP, calpain I was purified to homogeneity from rat or human erythrocyte cytosol. Figure $1 A$ depicts the polypeptide composition of the various human calpain I-containing fractions. As previously reported, the human erythrocyte calpain I consisted of 2 subunits, $M_{\mathrm{r}} 84$ $\mathrm{kDa}$ and $28 \mathrm{kDa}$, which were present in approximately a $1: 1 \mathrm{M}$ ratio (Murachi, 1983; Suzuki et al., 1987). This preparation was used to raise polyclonal antibodies. As shown in the immunoblot in Figure $1 B$, initial antisera contained antibodies only to the $M_{\mathrm{r}} 84 \mathrm{kDa}$ catalytic subunit and did not recognize the small chain that is also a subunit of calpain II. Rat erythrocyte calpain I was purified by the same method used to obtain the human enzyme, and then used to prepare a monoclonal antibody by conventional methods. Both the polyclonal and monoclonal an-

\section{A B C D E $F \quad G \quad M r \times 10^{-3}$}

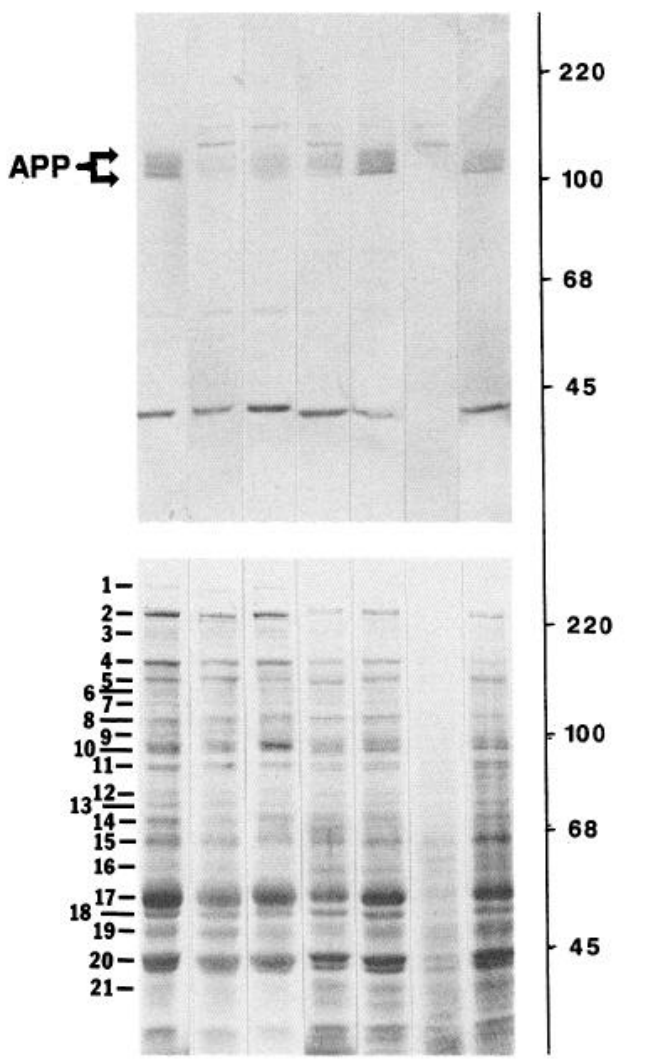

Figure 2. Degradation of rat brain membrane APP in vitro. Top, Immunoblot stained with an antiserum to the carboxy-terminal domain of APP. Membranes contain immunoreactive polypeptides at 110-130 $\mathrm{kDa}$ (a triplet), $65 \mathrm{kDa}$ and $40 \mathrm{kDa}$. Staining of the triplet represents specific recognition of APP, as it is abolished by preabsorption of the antiserum with immunogen (Siman et al., 1989a). Membranes were incubated with calpain I $(B, 450 \mathrm{ng} ; C, 90 \mathrm{ng})$, TPCK-treated trypsin $(D, 300 \mathrm{ng} ; E, 60 \mathrm{ng})$, papain $(F, 150 \mathrm{ng} ; G, 30 \mathrm{ng})$, or buffer alone $(A)$ at $22^{\circ} \mathrm{C}$. Reactions were run for $1 \mathrm{~min}$ (lanes $B, D$ ) or $5 \mathrm{~min}$ (lanes $A$, $C, E, F)$. The polypeptides of $M_{\mathrm{r}}>130 \mathrm{kDa}$ are proteolytic fragments of larger polypeptides that are stained nonspecifically. Bottom, Identical gel stained with Coomassie blue. The 21 major bands that were quantified are indicated on the left. Molecular weights (in kilodaltons) were determined using prestained protein standards (Bethesda Research Labs) and are listed on the right.

tibodies were used for immunohistochemical localization of calpain I, while the human protease was examined for its ability to degrade APP.

\section{Degradation of APP in vitro by various proteases}

Crude rat brain membranes were used as a source of APP, and APP degradation was assessed by quantitative immunoblotting following incubation with several exogenous proteases. The antiserum to the carboxy-terminal domain of APP and its use in Western blot studies have been previously described (Siman et al., 1989a). In this procedure, APP appears as a triplet of polypeptides of $M_{\mathrm{r}} 110-130 \mathrm{kDa}$, in agreement with Western blot and immunoprecipitation studies of others (Gandy et al., 1988; Selkoe et al., 1988; Schubert et al., 1989). The identification of these polypeptides as authentic APP was further confirmed (Lampe et al., 1989) by their ability to bind heparin (Schubert et al., 1989). 
CALPAIN I

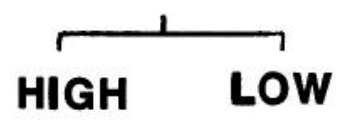

TRYPSIN

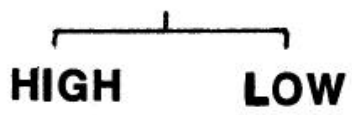

PAPAIN

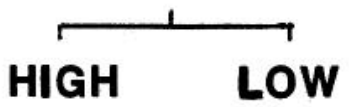

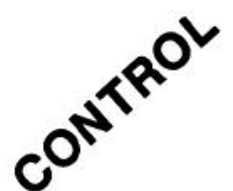

A

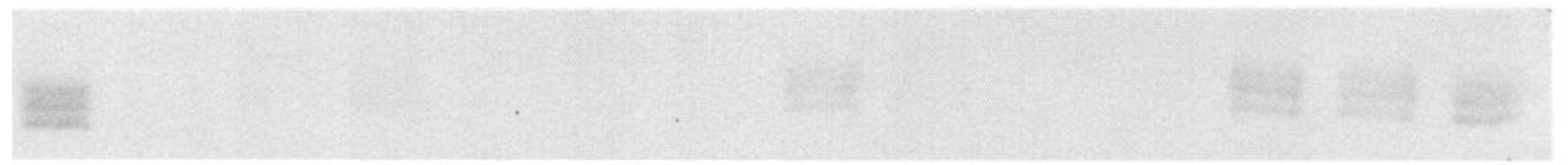

B

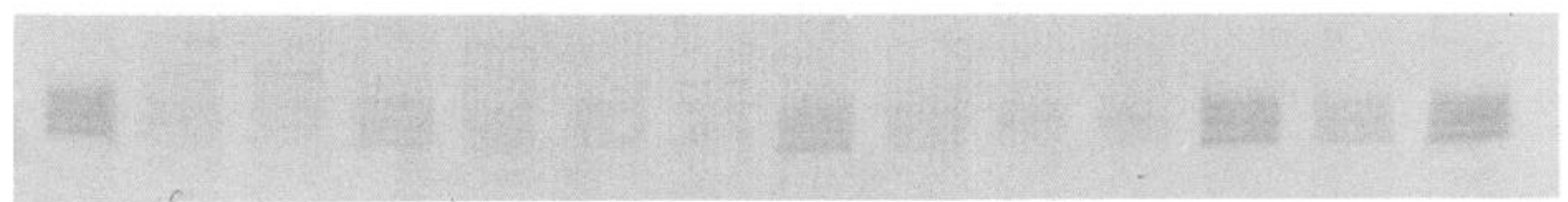

Figure 3. Comparison of degradation of soluble versus membrane-associated APP. A Trition X-100 extract of rat brain membranes $(A)$ or the membranes themselves $(B)$ were incubated with calpain I, TCPK-trypsin, or papain at the doses indicated in Figure 2 . For each dose of protease, reactions were performed at $22^{\circ} \mathrm{C}$ for $2 \mathrm{~min}$ (left lane of pair) or $5 \mathrm{~min}$ (right lane). Controls were incubated for $5 \mathrm{~min}$ in buffer alone. Shown is the region of a blot containing the 110-130 kDa triplet that was stained with an antiserum to APP. Note that under conditions that cause only a partial loss of membrane-bound APP (low doses of calpain I and trypsin, high dose of papain), solubilized APP levels decline to near the limit of detection.

All 3 proteases used, calpain I, trypsin, and papain, decreased APP levels (Fig. 2, top). The extent of APP loss depended on the amount of enzyme added and the duration of protease activation. As little as $30 \mathrm{ng}$ of protease (lane G) produced a readily detectable loss of APP from $70 \mu \mathrm{g}$ membrane protein. Papain (lanes F, G) was slightly more effective at degrading APP on a weight basis than either trypsin (lanes D, E) or calpain I (lanes B, C). Among the 3 resolvable APP polypeptides, there did not appear to be a preferential degradation or sparing by any of the 3 proteases.

The sensitivity of APP to proteolysis was compared with that of other membrane proteins by quantifying levels of the major Coomassie blue-stained polypeptides under conditions that caused APP degradation (Fig. 2, bottom). A dose of calpain I that decreased APP content by more than $80 \%$ had little effect on most major membrane polypeptides (lane B). Only bands 1, 2 , and 3 consistently declined by more than $50 \%$ following calpain I activation. Trypsin and papain also preferentially used APP as substrate. For example, trypsin (300 ng) caused a $76 \%$ decrease in APP levels (lane D), but among the 21 major polypeptides, only bands 1 and 2 declined to a greater extent (quantitative data not shown). Papain also potently degraded APP but showed less selectivity than either calpain I or trypsin. APP ranked as the best calpain I substrate among 22 polypeptides, the third best trypsin substrate, and the fourth best papain substrate.

While membrane-associated APP was highly sensitive to calpain I and other proteases, APP that had been solubilized was even more susceptible to degradation. APP released from membranes by Triton X-100 treatment was more effectively degraded by all 3 proteases examined (Fig. 3). Thus, calpain I, trypsin, and papain treatments that only partially reduced APP levels in membrane preparations (Fig. $3 B$ ) decreased the content of solubilized APP to near the limit of detection (Fig. 3A).

\section{Sites of calpain I cleavage of APP}

Immunopeptide mapping was used to identify the approximate locations of calpain I cleavagè of APP in vitro. For this analysis, APP was extracted from membranes, partially purified, and concentrated. On Western blots, the carboxy-terminal-directed antiserum labeled the triplet of APP polypeptides of $M_{\mathrm{r}} 110$ $130 \mathrm{kDa}$ and minor bands at 65,50 , and $30 \mathrm{kDa}$ (Fig. 4, lane A). Immunostaining of the triplet, but not the minor polypeptides, was eliminated by preabsorption of the antiserum with peptide immunogen (lane $A^{\prime}$ ). APP content decreased upon addition of calpain I and calcium (lanes B-E) but was unaffected in the absence of added calcium (lane F) or in the presence of the calpain inhibitor leupeptin (lane G). Addition of calcium in the absence of added calpain I did not alter APP levels (data not shown). These results indicate that the loss of APP was due to calpain I activation and not to the action of another protease contaminating the APP or calpain I preparations.

Calpain I activation produced 3 distinct, smaller APP fragments that reacted with antibodies to the carboxy-terminal domain. Mild activating conditions $(100 \mathrm{ng}, 5 \mathrm{~min})$ led to the formation of a complex of immunoreactive polypeptides of $M_{\mathrm{r}}$ $\sim 85-105 \mathrm{kDa}$ (Fig. 4, cleavage 1, lane E) and a small amount of a doublet of $M_{\mathrm{r}} \sim 60 \mathrm{kDa}$ (cleavage 2, lane $\mathrm{E}$ ). A larger dose of calpain I (500 ng) initially produced less of the $85-105 \mathrm{kDa}$ fragments and more of the $60 \mathrm{kDa}$ fragments (lane $\mathrm{B}, 1 \mathrm{~min}$ ), which, with time ( $5 \mathrm{~min})$, was replaced by a prominent immunoreactive $16 \mathrm{kDa}$ polypeptide (cleavage 3 , lane C). The decline of intact APP was accompanied by the appearance of smaller fragments with a near 1:1 $\mathrm{m}$ stoichiometry, indicating that these are the major cleavage products produced by calpain. Staining of the proteolytic fragments was not observed with antiserum that had been preabsorbed with peptide immunogen (lanes $\mathrm{B}^{\prime}, \mathrm{C}^{\prime}$ ), indicating that all of these polypeptides were derived from APP. 

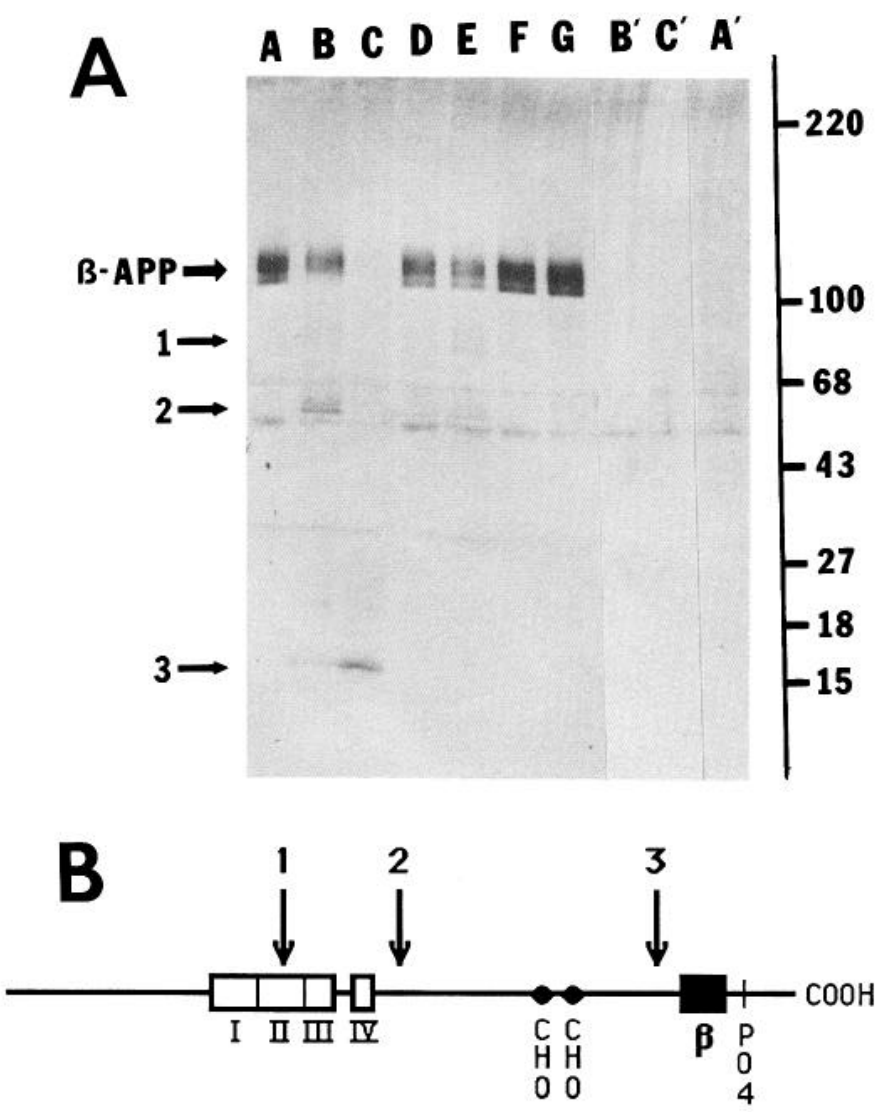

Figure 4. Calpain I cleavage sites in APP. A, Immunoblot of digests of soluble, partially purified APP, run on a 5-20\% linear gradient gel. Lanes $A, A^{\prime}$ : no protease; $B, B^{\prime}, C, C^{\prime}$ : calpain I, $500 \mathrm{ng} ; D, E$ : calpain I, $100 \mathrm{ng} ; F$ : calpain I, $500 \mathrm{ng}$, no calcium; $G$ : calpain I, $500 \mathrm{ng}$, + leupeptin, $100 \mu \mathrm{M}$. Lanes $A-G$ : antiserum 385 at $1: 300 ; A^{\prime}-C^{\prime}$ : antiserum 385 at $1: 300$, preabsorbed with peptide immunogen at $50 \mu \mathrm{g} / \mathrm{ml}$. Molecular weights of marker proteins (in $\mathrm{kDa}$ ) are shown on the right. Arrows on the left denote the intact $\beta$-APP triplet and the 3 sets of immunoreactive proteolytic fragments. $B$, Schematic diagram of primary structure of APP695, the isoform with no protease inhibitorcontaining inserts. The numbered arrows refer to the approximate locations of the 3 calpain I cleavage sites illustrated in $A$. Four probable PEST sequences (Siman and Christoph, 1989) are denoted by open boxes, while the $\beta$-amyloid peptide (Kang et al., 1987) is represented by the solid box. Also indicated are putative sites for glycosylation (CHO; Kang et al., 1987) and phosphorylation ( $\mathrm{PO}_{4}$; Gandy et al., 1988).

The 3 identified calpain I cleavage sites in APP are schematized in Figure $4 B$. The cleavage locations can only be approximated, because APP is post-translationally processed and exhibits an electrophoretic migration that is anomalous for the size of its polypeptide chain (Dyrks et al., 1989; Weidemann et al., 1989). Upon mild proteolysis, APP loses about $25 \mathrm{kDa}$, suggesting removal of an amino-terminal fragment of about 200 amino acids. Thus, the most preferred cleavage site is within the highly acidic domain, probably in the PEST sequences. More vigorous proteolysis removes about $55 \mathrm{kDa}$, suggesting cleavage near the middle of the polypeptide. This places the second cleavage site upstream from the putative $N$-glycosylated region. Continued proteolysis generates a major $16 \mathrm{kDa}$ carboxy-terminal fragment, placing the third cleavage site close to the aminoterminal of the $\beta$-amyloid peptide.

\section{Localizations of APP and calpain I in rat brain}

While calpain I has a high affinity for APP in vitro, it must also have access to APP in order to use the protein as substrate in vivo. We examined this issue by localizing APP and calpain I immunoreactivities. The distributions of both proteins in the rat central nervous system have been individually mapped previously (Siman et al., 1985; Hamakubo et al., 1986; Card et al., 1988); these studies suggest that both APP and calpain I are widely dispersed within circumscribed neuronal groups throughout the neuraxis. Here, we have localized the 2 proteins in adjacent sections from the entire rostro-caudal extent of the rat brain. Localization of each of the proteins was determined using 2 distinct antibodies: antibodies directed at the $\beta$-amyloid peptide and carboxy-terminal domains were used to localize APP, while calpain I distribution was analyzed with polyclonal antibodies to the catalytic subunit of the human erythrocyte protease and monoclonal antibodies to the rat erythrocyte enzyme. For each antigen, the 2 antibodies gave essentially identical patterns of staining.

Both APP and calpain I immunoreactivities were largely restricted to neurons, except for a small population of APP-positive cortical astrocytes, and were widely distributed throughout brain, as previously reported (Hamakubo et al., 1986; Card et al., 1988). Populations of neurons did, however, differ substantially from one another in staining intensities for either antigen, and, typically, those neurons containing the most intense APP immunoreactivity were also those stained most heavily for calpain $\mathrm{I}$.

The olfactory bulb represented the most striking example of a structure in which APP and calpain I immunoreactivities showed only a partial colocalization (Fig. 5, $A, B$ ). Mitral cells (mc) contained intense APP immunoreactivity, whereas the external plexiform (EP), glomerular (GL), and olfactory nerve layers $(\mathrm{ON})$ were relatively devoid of labeling. Although mitral cells also contained abundant calpain I immunoreactivity, the most concentrated calpain I staining was found in the axons of olfactory receptor cells comprising the olfactory nerve and terminating in the glomerular layer. The preferential localization of immunoreactivity for calpain I in the olfactory nerve and mitral cells, and for APP in mitral cells alone, is fully consistent with previous observations (Siman et al., 1985; Card et al., 1988). The olfactory bulb represents an exception in that the remainder of the forebrain exhibits a remarkable degree of overlap between APP and calpain I immunoreactivities. In the parietal cortex, large pyramidal neurons in layer 5 stained heavily for both antigens (Fig. $5 C, D$ ). Calpain I immunostaining was more prominent than that of APP in the primary apical dendrites of these neurons. Neurons in more superficial cortical layers stained less intensely for both antigens. In the hippocampal formation, APP and calpain I immunoreactivities were more prevalent in subicular neurons than in their neighboring pyramidal cells in area CA1 (Fig. 5, E, F). Neurons in the globus pallidus (Fig. 5, $G, H$ ) and entopeduncular nucleus (data not shown) also contained high levels of both APP and calpain I immunoreactivities.

While essentially all thalamic neurons stained for APP and calpain I, some cell groups, such as the anterodorsal (Fig. 6, $A$, $B$ ) and reticular thalamic nuclei (data not shown), stained more intensely for both antigens than did the surrounding neurons. Several hypothalamic nuclei, including the paraventricular and supraoptic, also contained abundant immunolabeling for APP and calpain I (data not shown). 

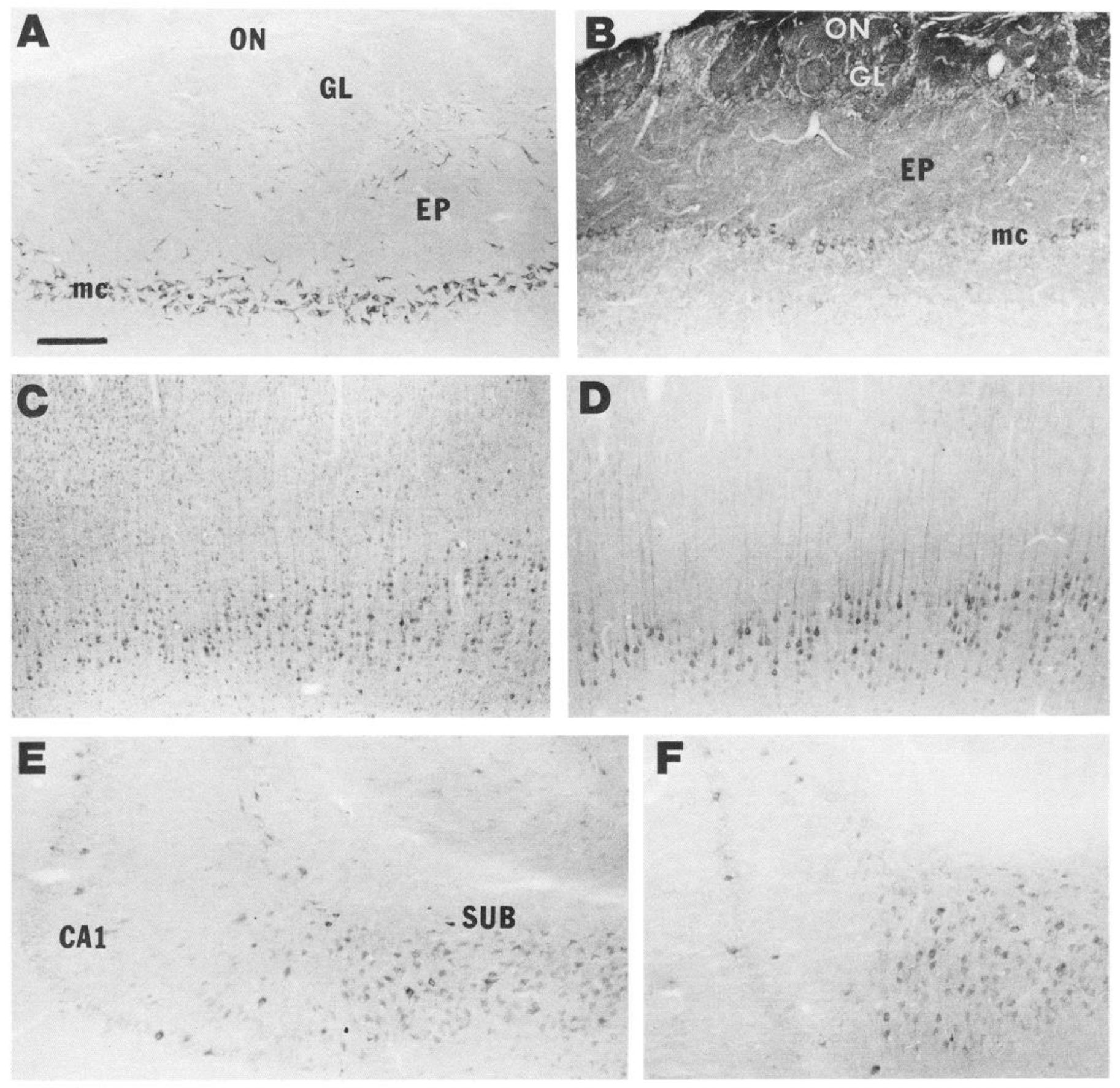

G
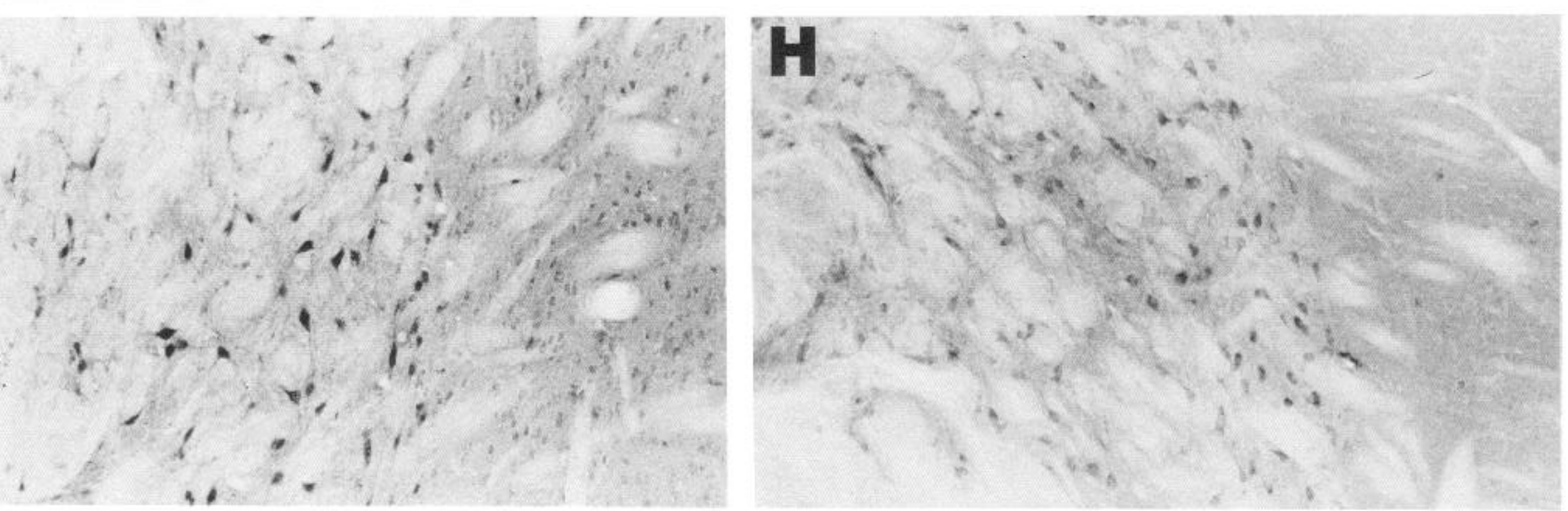

Figure 5. Immunohistochemical localizations of APP and calpain I in rat forebrain. Sagittal $(A, B, E, F)$ or coronal $(C, D, G, H)$ sections were stained with antibodies to APP $(A, C, E, G)$ or calpain I $(B, D, F, G) . A$ and $B$, olfactory bulb; mc: mitral cell layer; EP: external plexiform layer; GL: glomerular layer; ON: olfactory nerve. $C$ and $D$, parietal cortex. $E$ and $F$, hippocampus, area CA1, and subiculum (SUB). $G$ and $H$, globus pallidus. Scale bar: $200 \mu \mathrm{m}(A, B, E-H) ; 130 \mu \mathrm{m}(C, D)$. 

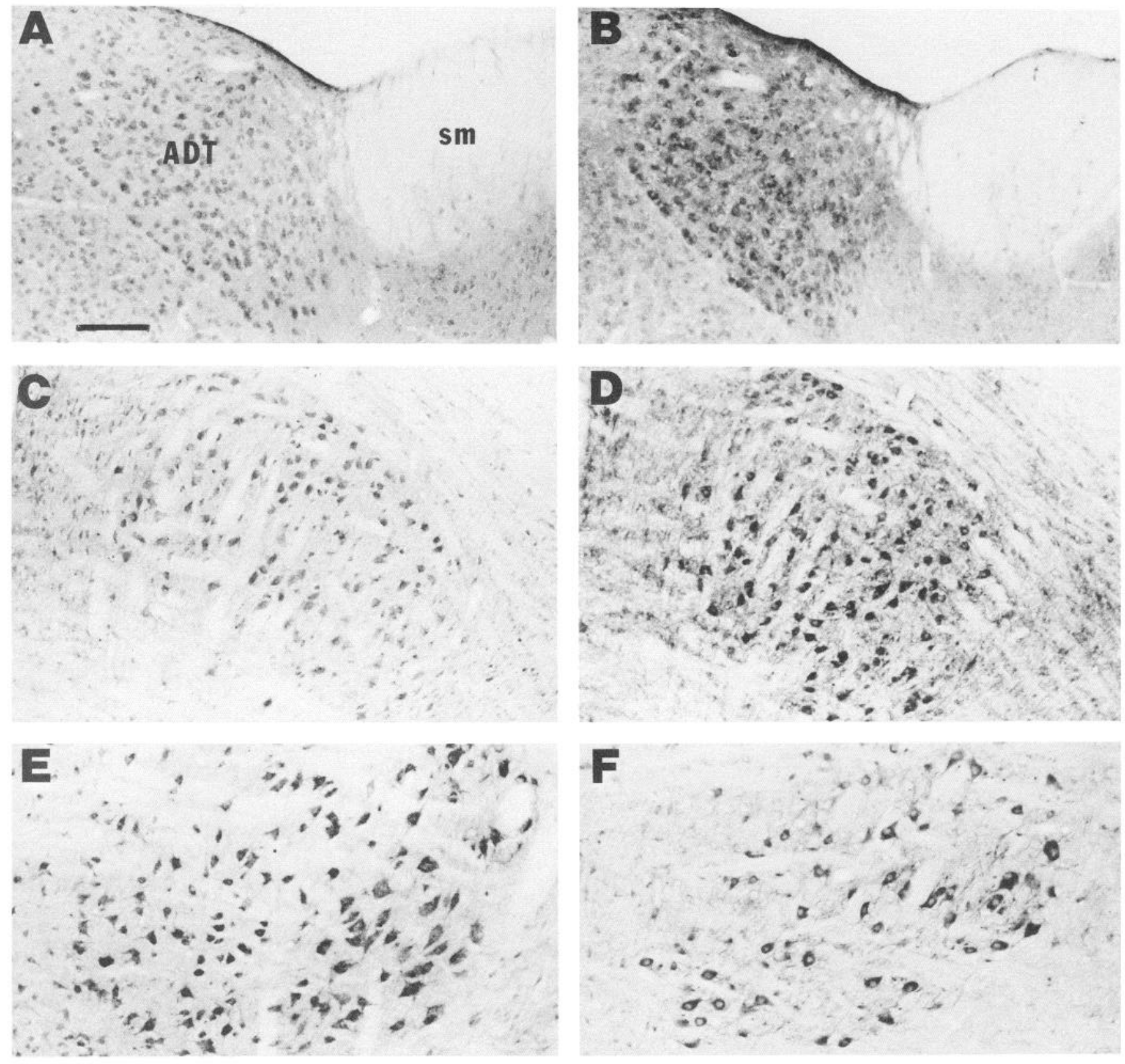

C

ml

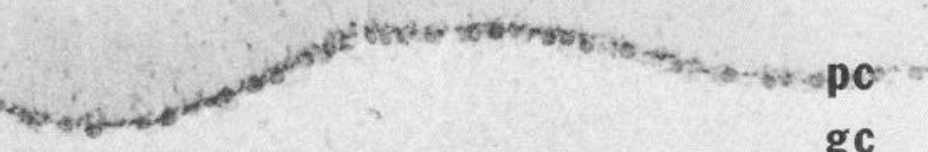

\section{H}

wm

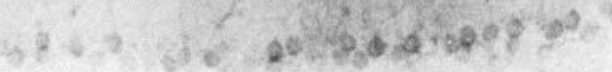



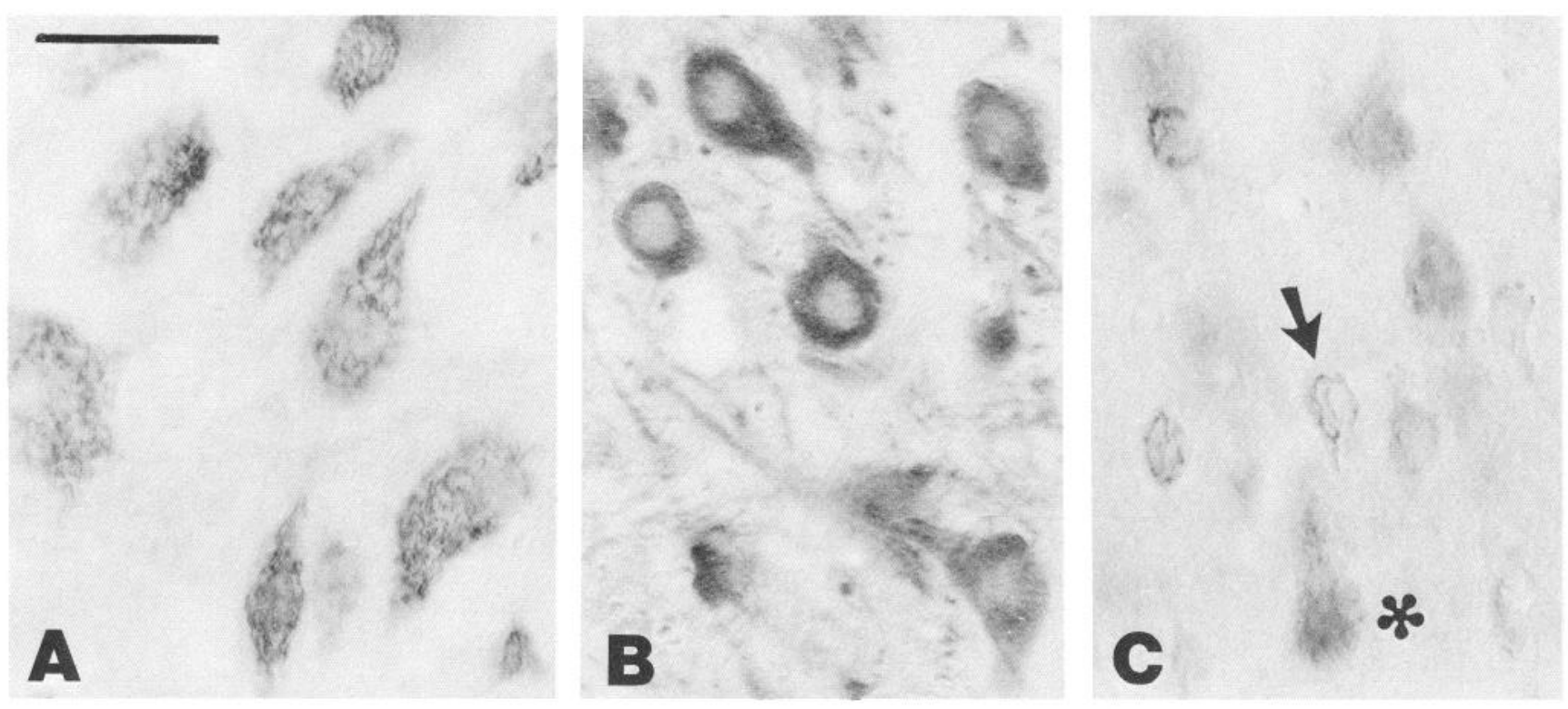

Figure 7. Subcellular localizations of APP and calpain I immunoreactivities. Sagittal sections illustrate the staining of neurons in motor trigeminal nucleus $(A, B)$ and cerebral cortex $(C) . A$ and $C$, APP. $B$, calpain I. Note that in motor trigeminal neurons $(A)$, APP immunoreactivity is localized to cytoplasmic filaments that surround the nucleus and extend into the most proximal portions of the primary dendrites. Calpain I immunoreactivity $(B)$ is diffusely distributed throughout the cytoplasm and is more prominent than that of APP in dendrites. Nuclei are also unstained for calpain I. Two other classes of the APP immunoreactive neuron are apparent in the cerebral cortex $(C)$ : those stained diffusely $(*)$ and those exhibiting a ring of label associated with the plasma membrane (arrow). Scale bar; $40 \mu \mathrm{m}$.

Large neurons in the midbrain and rostral brain stem were heavily stained for APP and calpain I. Figure 6 illustrates the labeled neuronal perikarya of the red nucleus (Fig. 6, C, D) and motor trigeminal nucleus (Fig. 6, $E, F$ ). In the cerebellum, immunolabeling for APP and calpain I was coextensive and gave a distinctly laminar appearance (Fig. 6, $G, H$ ). Both antigens were most prominent in the Purkinje cell layer, while the granule neurons were moderately stained and white matter axons only lightly labeled. Differences in antigen localization were observed in the molecular layer. Here, APP immunoreactivity was found in cell bodies of presumed basket and stellate interneurons, whereas calpain I labeling extended into the dendritic branches of Purkinje cells.

Although APP and calpain I immunoreactivities showed a remarkable co-distribution across a number of neuronal populations, the subcellular localizations of the 2 proteins were often distinct. Perikarya immunostained with antibodies to the carboxy-terminal domain of APP could be divided into 3 categories. Most frequently, neurons exhibited restricted, filamentous labeling (Fig. $7 A$ ). This type of labeling predominated in a number of cells, including mitral cells of the olfactory bulb, some dentate hilar neurons, Purkinje cells, and cells of the reticular thalamic, red, motor trigeminal, and deep cerebellar nuclei. In other cell types, APP immunostaining appeared more diffuse, particularly in many cortical and hippocampal neurons (Fig. $7 C{ }^{*}$ ). Therefore, in the majority of the neurons, APP is found intracellularly and is not strictly associated with the plasma membrane, as had been predicted on the basis of the primary amino acid sequence (Kang et al., 1987). However, occasional neurons did exhibit an annulus of APP immunoreactivity, apparently associated with the plasma membrane, most commonly in the cerebral cortex (Fig. $7 C$, arrow). In contrast to the frequent filamentous appearance of APP labeling, calpain I immunoreactivity was nearly always diffusely distributed throughout the cytoplasm, although it was excluded from the nucleus (Fig. $7 B$ ). This analysis is consistent with biochemical studies indicating that APP labeled with carboxy-terminal antibodies is primarily membrane-associated (Selkoe et al., 1988; Siman et al., 1989a), while calpain I is largely soluble (Murachi, 1983; Suzuki et al., 1987).

\section{Co-redistribution of APP and calpain I immunoreactivities following neuronal damage}

Because of the coextensive distribution of APP and calpain I immunoreactivities and the demonstration that APP is a preferred calpain I substrate, we examined the effect of a treatment known to alter APP distribution on the localization of calpain I. APP immunoreactivity is not normally observed in hippocampal astrocytes, but is aberrantly expressed by reactive astroglia following hippocampal neuronal damage (Siman et al., 1989a). Five days after the destruction of neurons by intraventricular injection of the excitotoxin kainate, APP immunopositive reactive glia were clustered around the site of neuronal loss in ipsilateral area CA3 (Fig. 8C). Similarly, calpain I immunoreactivity, which is normally confined to hippocampal neurons (Fig. $8 A$; Hamakubo et al., 1986) also aberrantly ap-

Figure 6. Immunohistochemical localization of APP and calpain I in diencephalon, mesencephalon, and rhombencephalon. Coronal $(A, B)$ or sagittal $(C-H)$ sections were stained using antibodies to APP $(A, C, E, G)$ or calpain $\mathrm{I}(B, D, F, H) . A$ and $B$, dorsal thalamus; ADT: anterodorsal thalamic nucleus; SM: stria medullaris. $C$ and $D$, red nucleus. $E$ and $F$, motor trigeminal nucleus. $G$ and $H$, cerebellum; ml: molecular layer; pc: Purkinje cell layer; gc: granule cell layer; wm: white matter. Scale bar: $200 \mu \mathrm{m}(A, B, E-H), 130 \mu \mathrm{m}(C, D)$. 

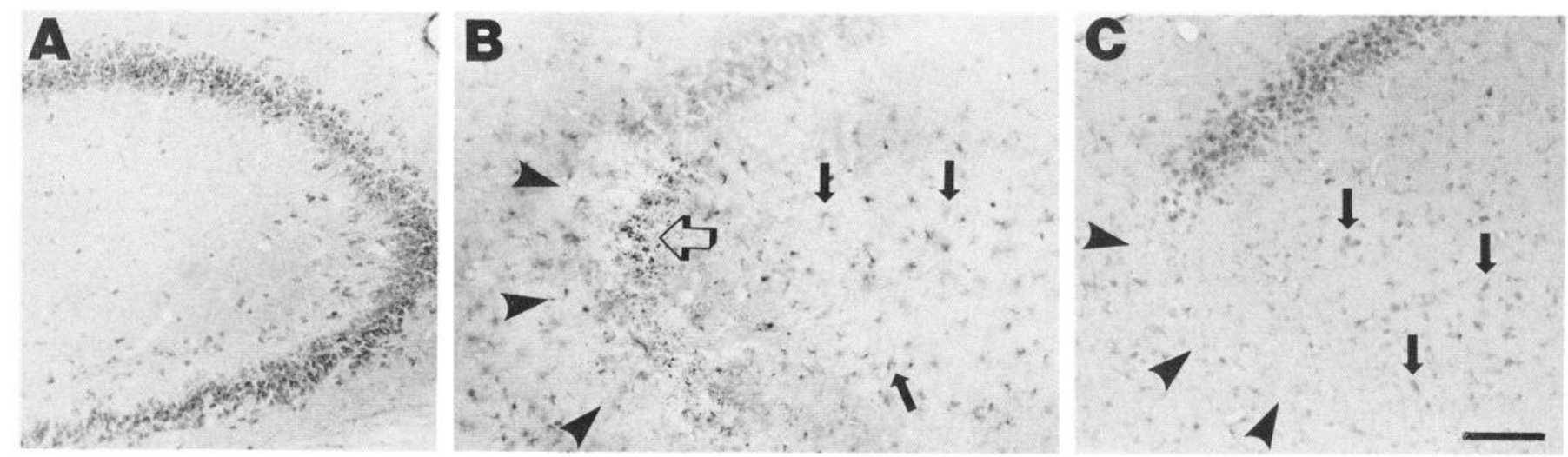

Figure 8. Localization of APP and calpain I immunoreactivities in reactive astrocytes following hippocampal neuronal damage. Coronal sections of the dorsal hippocampus from a rat injected $5 \mathrm{~d}$ earlier with $0.5 \mu \mathrm{g}$ kainate (i.c.v.), and labeled with antibodies to calpain I $(A, B)$ or APP (C). $A$, contralateral area CA3. $B$ and $C$, ipsilateral are CA3. Arrowheads denote zone of neuronal necrosis. Arrows identify some of the immunostained reactive astroglia positive for APP $(C)$ and calpain I $(B)$. Punctate calpain I immunoreactivity also appears in the stratum lucidum in the mossy fiber terminal zone $(B$, open arrow). Scale bar: $100 \mu \mathrm{m}(B, C) ; 65 \mu \mathrm{m}(A)$.

peared in reactive astrocytes (Fig. $8 B$, arrows). Additional punctate calpain I immunoreactivity was observed in the stratum lucidum of area CA3 (Fig. $8 B$, open arrow), normally the termination zone of the mossy fiber projection.

\section{APP loss in vivo under calpain I-activating conditions}

If calpain I is indeed involved in the turnover of neuronal APP in vivo, then activation of neuronal calpain I should lead to increased degradation of APP. Injection of kainate initially causes activation of calpain I in neurons destined to degenerate (Siman and Noszek, 1988; Siman et al., 1989b) and subsequently produces neuronal damage, reactive gliosis, and aberrant APP and calpain I expression after several days. We quantified hippocampal APP levels by immunoblot analysis $24 \mathrm{hr}$ after intraventricular infusion of kainate or saline vehicle, and we compared these levels with the APP content of untreated hippocampus. The vehicle alone did not alter hippocampal APP content, so values from this group were combined with the uninjected group. After $24 \mathrm{hr}$, APP content in the kainate-treated group, expressed per unit protein, had declined $32 \%$ (Fig. 9). The decrease is statistically significant $(p<0.005)$. The APP decrease is selective in that the same experimental treatment does not alter the content of a number of other hippocampal polypeptides (Siman and Noszek, 1988).

\section{Discussion}

The $\beta$-amyloid peptide found in plaque cores has the dual properties of being both extraordinarily resistant to proteolytic attack and highly insoluble (Allsop et al., 1983; Castano et al., 1986; Kirschner et al., 1987). As a consequence, the $\beta$-peptide probably cannot be cleared once generated. Because $\beta$-amyloid deposits are not normally found in the mature brain, it seems likely that processing mechanisms exist which break down APP without releasing the $\beta$-peptide. This processing may go awry in Alzheimer's disease and may be a critical event in the pathogenesis of amyloid plaques (Carrell, 1988). As a first step toward understanding the normal and pathological processing of APP, we have examined the possible role of calpain I in APP degradation. We have found that calpain I preferentially uses rat brain APP as substrate, colocalizes with APP in many popu- lations of neurons throughout the brain and in reactive glia following neuronal damage, and may function in vivo to couple neuronal activation with changes in the rate of APP breakdown.

APP is a member (Siman and Christoph, 1989) of the family of proteins containing PEST sequences (Rogers et al., 1986; Rechsteiner et al., 1987). This primary structure motif is highly predictive of proteins that are rapidly turning over, suggesting that APP may have a short half-life and may be particularly sensitive to proteolysis. It has been hypothesized that proteins with PEST sequences may be rapidly degraded because of an extraordinary sensitivity to calpain (Rogers et al., 1986). The 2 calpain variants, I and II, are differentially distributed in brain, with calpain I being the form primarily expressed in neuronal perikarya (Hamakubo et al., 1986; Nixon, 1986). Similar to calpain I, APP immunoreactivity is normally found in rat brain almost exclusively in neurons (Card et al., 1988). Accordingly, we focused on the processing of APP by calpain I.

As expected of proteins with PEST domains, membrane-bound APP was exquisitely protease-sensitive. Doses of calpain I, trypsin, or papain that caused only minor breakdown of most membrane proteins produced substantial destruction of APP. Compared with 21 Coomassie blue-stained polypeptides, APP was the most sensitive calpain I substrate (Fig. 2). Not unexpectedly, solubilized APP was even more protease-sensitive, presumably as a result of a release of the preferred or additional cleavage sites from steric hindrance. These findings provide evidence that APP may be rapidly turned over in neurons. Indeed, initial measurements of APP turnover in cultured cells indicate that at least a fraction of APP has a very short half-life of 20-30 min (Weidemann et al., 1989). Moreover, our results are consistent with the postulate that proteins with PEST domains are unusually susceptible to degradation by calpain. It will be of interest to determine if other PEST sequence-containing proteins of importance to neuronal function, such as the proto-oncogene product c-fos (Sagar et al., 1988), are also preferential targets of calpain I.

Immunopeptide mapping revealed 3 distinct cleavage events in calpain I-mediated APP degradation. Although the cleavage locations can only be approximated from this type of analysis, they nevertheless reveal significant features of calpain action on APP. The most calpain I-sensitive site is located within the large 


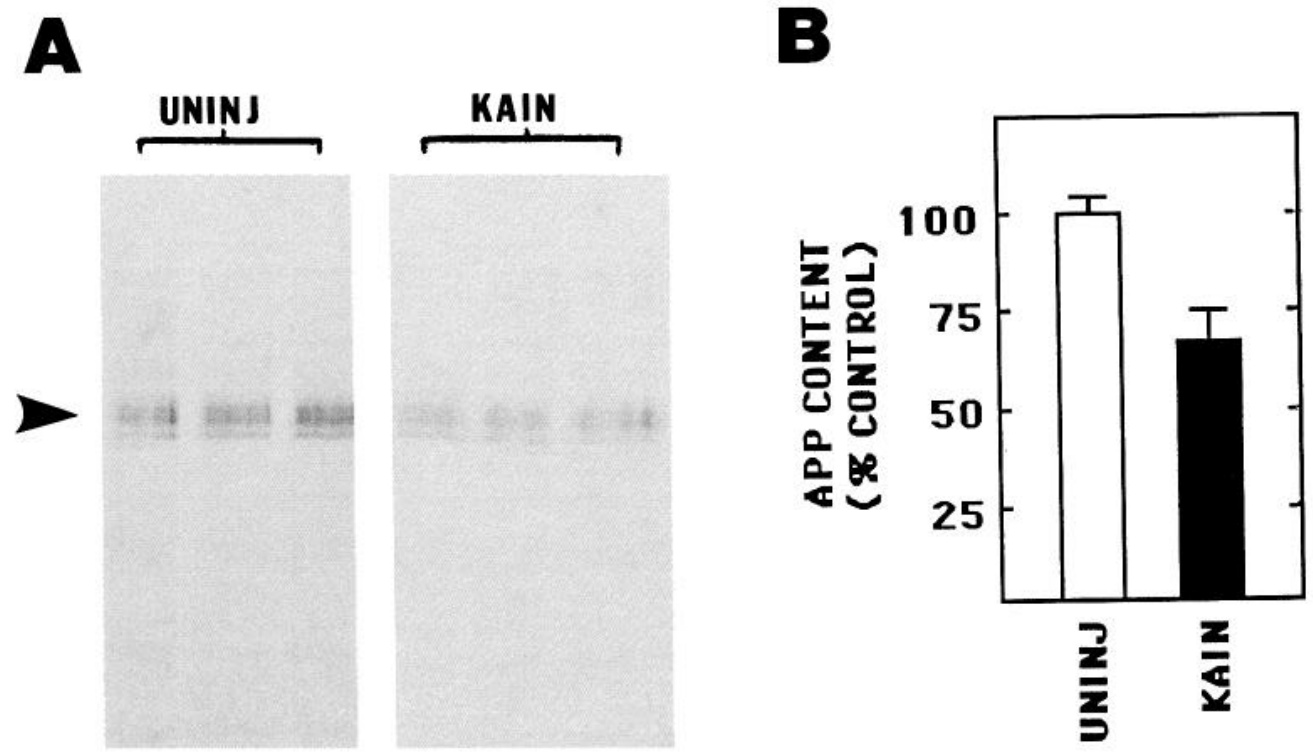

Figure 9. Decrease in hippocampal APP content after intraventricular kainate infusion. $A$, Immunoblot of representative experiment showing that, $24 \mathrm{~h}$ after inventricular kainate administration, the ipsilateral hippocampus contained decreased levels of the APP 110-130 kDa polypeptides. Uninj: control hippocampus from uninjected rats; kain: hippocampus ipsilateral to kainate infusion. The arrowhead points to the APP triplet. $B$, Summary of quantitative immunoblot analysis from 12 control rats (4 saline injected, 8 uninjected) and 10 rats treated with kainate. Values are the means \pm SEM. APP levels (per unit total protein) declined $32 \%$ after $24 \mathrm{~h}$ with kainate treatment. The decrease is statistically significant $(p<0.005, t$-test).
PEST sequence in the highly acidic domain. Two other proteins containing probable PEST sequences, hydroxymethyl-glutaryl coenzyme A-reductase (Liscum et al., 1985) and type I protein kinase C (Kishimoto et al., 1989), are also cleaved by calpain near or within their PEST domains, suggesting that not only are PEST regions predictive of high-affinity calpain substrates, but of calpain cleavage location as well. Under conditions of more vigorous proteolysis, 2 additional calpain I cleavages of APP generate carboxy-terminal fragments of about 60-65 kDa and $16 \mathrm{kDa}$. The former cleavage removes an amino terminal 50 $\mathrm{kDa}$ fragment, splitting the molecule approximately in half. The $16 \mathrm{kDa}$ carboxy-terminal fragment generated by cleavage at site 3 likely contains the entire $\beta$-amyloid peptide and is identical in size to the carboxy-terminal portion that is reportedly cleaved from the APP fragment destined for release from cultured cells (Weidemann et al., 1989). Because only APP fragments containing the carboxy-terminal are detected by the method we have employed, additional cleavage pathways to the one described here are possible. However, the prevalence of the 50 and $16 \mathrm{kDa}$ fragments strongly suggests that they represent the predominant products of calpain I-mediated APP breakdown. Further processing of the $16 \mathrm{kDa}$ carboxy-terminal $\beta$-peptidecontaining fragment is currently under investigation.

The possible generation of a $16 \mathrm{kDa}$ carboxy-terminal APP fragment by calpain I has relevance to neuropathologies other than Alzheimer's disease. This calpain-generated fragment is nearly identical to a recombinant APP segment that reportedly is neurotoxic (Yanker et al., 1989). Calpain activation has previously been hypothesized to play a key role in producing neuronal structural damage associated with excitotoxicity (Siman and Noszek, 1988; Siman et al., 1989b). It is intriguing to speculate that excessive calpain I activation may destroy neurons by generating a neurotoxic fragment of APP. Clearly, it must be determined whether the calpain-generated APP fragment is also toxic to neurons and whether it is produced by experimental treatments that cause neuronal degeneration.

The trio of APP bands resolvable by the Western blot procedure may represent distinct isoforms of the APP polypeptide (Kitaguchi et al., 1988; Ponte et al., 1988; Tanzi et al., 1988) or a single polypeptide with different states of glycosylation (Weidemann et al., 1989) or phosphorylation (Gandy et al., 1988). These APP variants may be differentially processed and, in particular, the presence of a domain with trypsin inhibitory activity in 2 of the isoforms (Kitaguchi et al., 1988) may lead to differences in processing mechanisms. We could find no evidence for differential sparing or degradation of any of the 3 resolvable polypeptides by any protease, including trypsin (Fig. $2,3)$. However, antibodies to portions of APP other than the carboxy-terminal may provide a different picture of APP degradation by trypsin or other serine proteases.

In order for calpain I-induced APP degradation to be a physiologically or pathologically relevant process in vivo, calpain must have access to its APP cleavage sites. Our observations suggest that this is the case, but they do not provide conclusive proof that APP is accessible to activated calpain. First, we compared APP and calpain I distributions in the normal adult rat brain by light microscopic immunohistochemistry. The present analysis confirms previous observations that APP and calpain I immunoreactivities are widely dispersed among nearly all types of neurons (Hamakubo et al., 1986; Card et al., 1988; Siman et al., 1989a) and demonstrates that the intensity of labeling varies considerably from cell type to cell type (Figs. 5, 6). Strikingly, those cell populations staining most intensely for APP also were the most heavily labeled for calpain I.

Within neurons, both APP and calpain I immunoreactivities were prominent in perikarya, but at high magnification the subcellular localizations of the 2 antigens could often be distinguished. Whereas calpain I immunoreactivity appeared diffuse, APP immunolabeled with carboxy-terminal antibodies frequently had a filamentous appearance (Fig. 7). Ultrastructural studies have identified these APP stained elements as Golgi stacks (J. P. Card, R. P. Meade, L. G. Davis, and R. Siman, unpublished observations). However, in other neurons APP immunoreactivity appeared diffuse or formed an annulus associated with the plasma membrane (Fig. 7C). Antibodies to APP domains other than the carboxy-terminal failed to exhibit the selective Golgi association, suggesting that, in some neurons, the carboxy-terminal portion of APP may be cleaved at the 
Golgi and remain there (Card et al., unpublished observation). These data are consistent with the recent findings that the large amino-terminal portion of APP undergoes fast axonal transport (Koo et al., 1990) and is identical to protease nexin II, a secreted growth rcgulating protein (Oltersdorf et al., 1989; Van Nostrand et al., 1989). When taken together, the results suggest that calpain I may have access to neuronal APP, particularly in those cells in which APP is diffusely localized throughout the cell bodies. A further possibility is that calpain I may have ready access to APP when the 2 proteins are released upon neuronal death.

A second finding implicating calpain $I$ in the processing of APP is the redistribution of both protease and substrate into reactive astrocytes following neuronal damage (Fig. 8). We have previously shown that APP immunoreactivity becomes aberrantly expressed in reactive astrocytes that surround sites of neuronal damage (Siman et al., 1989a). Here, calpain I immunoreactivity, which, like that for APP, is normally confined in the hippocampus to neurons (Siman et al., 1985; Hamakubo et al., 1986), also appears in reactive astroglia $5 \mathrm{~d}$ following kainate-induced hippocampal neuronal destruction. Thus, calpain I-mediated APP processing may not be restricted to neurons but may occur in non-neuronal cells, as well, under pathological conditions. It is intriguing that neuronal loss and reactive gliosis are common features of areas of the Alzheimer's diseased brain afflicted with large numbers of plaques (Schechter et al., 1981; Price, 1986). Conceivably, reactive glia may be a source of $\beta$-amyloid that is deposited into plaques, and calpain I could be involved in generating the peptide in these cells. Alternatively, processing of APP by calpain I may be important for prevention of $\beta$-peptide formation, and the presence of the protease in reactive glia could serve a protective function. An ultrastructural analysis of the 2 proteins in reactive astroglia may be required to confirm that calpain I has access to APP in these cells.

Further indirect evidence for calpain involvement in APP proccssing comes from in vivo experiments using intracranial administration of excitatory amino acids. APP levels in the hippocampus decrease following intraventricular infusion of kainate (Fig. 9), a treatment that rapidly activates hippocampal calpain I and selectively decreases the content of calpain substrates (Siman and Noszek, 1988; Siman et al., 1989b). However, because proteolytic fragments of APP could not be detected in these experiments, decreases in APP for reasons other than enhanced proteolysis cannot be completely ruled out. Additional support for a rapid APP degradation comes from immunocytochemical analysis of APP. In as little as $4 \mathrm{~h}$ after kainate injection, APP immunoreactivity disappears from area CA3 neurons that are destined to degenerate over the next several days (Siman et al., 1989a). When this finding is coupled with the colocalization of calpain I and APP in the same cells, the extreme sensitivity of APP to the protease in vitro, and the capacity of calpain I to generate an APP fragment found normally in cultured cells, it strongly suggests that calpain $I$ is involved in APP processing. If the kainate-induced APP loss does result from increased proteolysis, it suggests a mechanism whereby neuronal activity may act through calcium influx and calpain I activation to control APP catabolism. Thus, excitatory amino acids should be given consideration not only for their involvement in the neuronal loss accompanying Alzheimer's disease (Maragos et al., 1987), but for their possible role in regulating APP metabolism and protease nexin II and $\beta$-amyloid formation, as well.

\section{References}

Abraham CR, Selkoe DJ, Potter H (1988) Immunochemical identification of the serine protease inhibitor $\alpha_{1}$-antichymotrypsin in the brain amyloid deposits of Alzheimer's disease. Cell 52:487-501.

Allsop D, Landon M, Kidd M (1983) The isolation and amino acid composition of senile plaque core protein. Brain Res 259:348-352.

Bowen DM, Davison AN (1973) Cathepsin A in human brain and spleen. Biochem J 131:417-419.

Bradford MM (1976) A rapid and sensitive method for the quantification of microgram quantities of protein utilizing the principle of protein-dye binding. Anal Biochem 72:248-254.

Card JP, Meade RP, Davis LG (1988) Immunocytochemical localization of the precursor protein for $\beta$-amyloid in the rat central nervous system. Neuron 1:835-846.

Carrell RW (1988) Alzheimer's disease: enter a protease inhibitor. Nature 331:478-479.

Castano EM, Ghiso J, Prelli F, Gorevic PD, Migheli A, Frangione B (1986) In vitro formation of amyloid fibrils from two synthetic peptides of different lengths homologous to Alzheimer's disease $\beta$-protein. Biochem Biophys Res Commun 141:782-789.

Croall DE, DeMartino GN (1983) Purification and characterization of calcium-dependent proteases from rat heart. J Biol Chem 258: 5660-5665.

Dyrks T, Weidemann A, Multhaup G, Salbaum JM, Lemaire H-G, Kang J, Muller-Hill B, Masters CL, Beyreuther K (1989) Identification, transmembrane orientation and biogenesis of the amyloid A4 precursor of Alzheimer's disease. EMBO J 7:949-957.

Gandy S, Czernik AJ, Greengard P (1988) Phosphorylation of Alzheimer's disease amyloid precursor peptide by protein kinase $\mathrm{C}$ and $\mathrm{Ca}^{2+} /$ calmodulin-dependent protein kinase II. Proc Natl Acad Sci USA 85:6218-6222.

Glenner GG, Wong CW (1984) Alzheimer's disease and Down's syndrome: sharing of a unique cerebrovascular amyloid fibril protein. Biochem Biophys Res Commun 122:1131-1135.

Glenner GG, Wong CW (1987) Amyloidosis in Alzheimer's disease and Down's syndrome. In: Banbury report 27: molecular neuropathology of aging (Davies P, Finch CE, eds), pp 253-255. New York: Cold Spring Harbor Laboratory.

Goding JW (1986) Monoclonal antibodies: principles and practice. London: Academic.

Goldgaber D, Lerman MI, McBride OW, Saffiotti U, Gajdusek DC (1987) Characterization and chromosomal localization of a cDNA encoding brain amyloid of Alzheimer's disease. Science 235:877-880.

Grundke-Iqbal I, Iqbal K, George L, Tung Y-C, Kim KS, Wisniewski HM (1989) Amyloid protein and neurofibrillary tangles coexist in the same neuron in Alzheimer's disease. Proc Natl Acad Sci USA 86: 2853-2857.

Hamakubo T, Kannagi R, Murachi T, Matus A (1986) Distribution of calpains I and II in rat brain. J Neurosci 6:3103-3111.

Kang J, Lemaire HG, Unterbeck A, Salbaum JM, Masters CL, Grzeschik KH, Multhaun G, Beyreuther K, Muller-IHill B (1987) The precursor of Alzheimer's disease amyloid A4 protein resembles a cellsurface receptor. Nature 325:733-736.

Kirschner DA, Inouye H, Duffy LK, Sinclair A, Lind M, Selkoe DJ (1987) Synthetic peptide homologous to $\beta$ protein from Alzheimer's disease forms amyloid-like fibrils in vitro. Proc Natl Acad Sci USA 84:6953-6957.

Kishimoto A, Mikawa K, Hashimoto K, Yasuda I, Tanaka S, Tominaga M, Kuroda T, Nishizuka Y (1989) Limited proteolysis of protein kinase $C$ subspecies by calcium-dependent neutral protease (calpain). J Biol Chem 264:4088-4092.

Kitaguchi N, Takahashi Y, Tokushima Y, Shiojiri S, Ito H (1988) Novel precursor of Alzheimer's disease amyloid protein shows protease inhibitory activity. Nature 331:530-532.

Koo EH, Sisodia SS, Archer DR, Martin LJ, Weidemann A, Beyreuther K, Fischer P, Masters CL, Price DL (1990) Precursor of amyloid protein in Alzheimer's disease undergoes fast anterograde axonal transport. Proc Natl Acad Sci USA 87:1561-1565.

Lampe R, Davis LG, Card JP, Siman R (1989) Characterization and 
partial purification of the $\beta$-amyloid precursor protein from rat brain. Neurosci Abstr 15:1377.

Liscum L, Finer-Moore J, Stroud R, Luskey K, Brown M, Goldstein J (1985) Domain structure of 3-hydroxy-3-methylglutaryl coenzyme A reductase, a glycoprotein of the endoplasmic reticulum. J Biol Chem 260:522-530.

Maragos WF, Greenamyre T, Penney JB Jr, Young AB (1987) Glutamate dysfunction in Alzheimer's disease: an hypothesis. Trends Neurosci 10:65-68.

Masters CL, Simms G, Weinman NA, Multhaup G, McDonald BL, Beyreuther K (1985) Amyloid plaque core protein in Alzheimer's disease and Down's syndrome. Proc Natl Acad Sci USA 82:42454249.

Murachi T (1983) Calpain and calpastatin. Trends Biochem Sci 8: 167-169.

Nelson RB, Siman R (1989) Identification and characterization of calcium-stimulated metalloproteases in rat brain. I Neurochem 41: 641-647.

Nelson RB, Siman R (1990) Clipsin: a chymotrypsin-like serine protease in rat brain which is irreversibly inhibited by alpha-1-antichymotrypsin. J Biol Chem 265:3836-3843.

Nixon RA (1986) Fodrin degradation by calcium-activated neutral proteinase (CANP) in retinal ganglion cell neurons and optic glia: preferential localization of CANP activities in neurons. J Neurosci 6: 1264-1271.

Oltersdorf T, Fritz LC, Schenk DB, Lieberburg I, Johnson-Wood KL, Beattie EC, Ward PJ, Blacher RW, Dovey HF, Sinha S (1989) The secreted form of the Alzheimer's amyloid precursor protein with the Kunitz domain is protease nexin II. Nature 341:141-145.

Ponte P, Gonzalez-DeWhitt P, Schilling J, Miller J, Hsu D, Greenberg B, Davis K, Wallace W, Lieberburg I, Fuller F, Cordell B (1988) A new A4 amyloid mRNA contains a domain homologous to serine proteinase inhibitors. Nature 331:525-527.

Price DL (1986) New perspectives in Alzheimer's disease. Ann Rev Neurosci 9:489-512.

Rechsteiner M, Rogers S, Rote K (1987) Protein structure and intracellular stability. Trends Biochem Sci 12:390-394.

Robakis NK, Ramakrishna N, Wolfe G, Wisniewski HM (1987) Molecular cloning and characterization of a cDNA encoding the cerebrovascular and the neuritic plaque amyloid peptides. Proc Natl Acad Sci USA 84:4190-4194.

Rogers S, Wells R, Rechsteiner M (1986) Amino acid sequences common to rapidly degraded proteins: the PEST hypothesis. Science 234: 364-368.

Sagar SM, Sharp FR, Curran T (1988) Expression of c-fos protein in brain: metabolic mapping at the cellular level. Science 240:13281331.

Schechter R, Yen S-H, Terry RD (1981) Fibrous astrocytes in senile dementia of the Alzheimer type. J Neuropath Exp Neurol 40:95-101.

Schubert D, LaCorbiere M, Saitoh T, Cole G (1989) Characterization of an amyloid $\beta$ precursor protein that binds heparin and contains tyrosine sulfate. Proc Natl Acad Sci USA 86:2066-2069.

Selkoe DJ, Podlisny MB, Joachim CL, Vickers EA, Lee G, Fritz LC, Oltersdorf $T$ (1988) $\beta$-amyloid precursor protein of Alzheimer's disease occurs as 110 - to 135 -kiloDalton membrane-associated proteins in neural and nonneural tissues. Proc Natl Acad Sci 85:73417345.

Siman R, Christoph G (1989) Beta-amyloid precursor is a PEST protein. Biochem Biophys Res Commun 165:1299-1304.
Siman R, Noszek JC (1988) Excitatory amino acids activate calpain I and induce structural protein breakdown in vivo. Neuron 1:279287.

Siman R, Gall C, Perlmutter LS, Christian C, Baudry M, Lynch G (1985) Distribution of calpain I, an enzyme associated with degenerative activity, in rat brain. Brain Res 347:399-403.

Siman R, Card JP, Nelson RB, Davis LG (1989a) Expression of $\beta$-amyloid precursor protein in reactive astrocytes following neuronal damage. Neuron 3:275-285.

Siman R, Noszek JC, Kegerise C (1989b) Calpain I activation is specifically related to excitatory amino acid induction of hippocampal damage. J Neurosci 9:1579-1590.

Simonson L, Baudry M, Siman R, Lynch G (1985) Regional distribution of soluble calcium-activated proteolytic activity in neonatal and adult rat brain. Brain Res 327:153-159.

Slater EE, Defendini R, Zimmerman EA (1980) Wide distribution of immunoreactivity renin in nerve cells of human brain. Proc Natl Acad Sci USA 77:5458-5460.

Soreq H, Miskin R (1983) Plasminogen activator in the developing rat cerebellum: biosynthesis and localization in granular neurons. Brain Res 313:149-158.

Suhar A, Marks N (1979) Purification and properties of brain cathepsin B. Evidence for cleavage of pituitary hormones. Eur J Biochem 101: 23-30.

Suzuki K, Imajoh S, Emori Y, Kawasaki H, Minami Y, Ohno S (1987) Calcium-activated neutral protease and its endogenous inhibitor: activation at the cell membrane and biological function. FEBS Lett 220: 271-277.

Tanzi RE, Gusella JF, Watkins PC, Bruns GA, St. George-Hyslop P Van Keuren ML, Patterson D, Pagan S, Kurnit DM, Neve RL (1987) Amyloid beta protein gene: cDNA, mRNA distribution, and genetic linkage near the Alzheimer locus. Science 235:880-884.

Tanzi RE, McClatchey AI, Lampert ED, Villa-Komaroff L, Gusella JF, Neve RL (1988) Protease inhibitor domain encoded by an amyloid protein precursor mRNA associated with Alzheimer's disease. Nature 331:528-530.

Terry RD, Katzman R (1983) Senile dementia of Alzheimer type: defining a disease. In: The neurology of aging (Katzman R, Terry RD, eds), pp 51-84. Philadelphia: Davis.

Van Nostrand WE, Wagner SL, Suzuki M, Choi BH, Farrow JS, Geddes JW, Cotman CW, Cunningham DD (1989) Protease nexin II, a potent anti-chymotrypsin, shows identity to amyloid $\beta$-protein precursor. Nature 341:546-549.

Weidemann A, Konig G, Bunke D, Fischer P, Salbaum JM, Masters CL, Beyreuther K (1989) Identification, biogenesis and localization of precursors of Alzheimer's disease A4 amyloid protein. Cell 57: $115-126$.

Westerwoudt RJ (1986) Factors affecting production of monoclonal antibodies. Meth Enzymol 121:3-18.

Whitaker JN, Seyer JM (1979) Isolation and characterization of bovine brain cathepsin D. J Neurochem 32:325-333.

Yanker BA, Dawes LR, Fisher S, Villa-Komaroff L, Oster-Granite ML, Neve RL (1989) Neurotoxicity of a fragment of the amyloid precursor associated with Alzheimer's disease. Science 245:417-420.

Yoshimura N, Kikuchi T, Sasaki T, Kitahara A, Hatanaka M, Murachi $\mathrm{T}$ (1983) Two distinct $\mathrm{Ca}^{2+}$ proteases (calpain I and calpain II) purified concurrently by the same method from rat kidney. J Biol Chem 258:8883-8889. 